\title{
The Modulatory Role of Aqueous Extract of Vernonia Amygdalina Extract on Pregnant Rats
}

\author{
Isa, A. I. ${ }^{1}$, Bako, I. G. ${ }^{1}$, Saleh, M. I. A ${ }^{1}$, Mohammed, A $^{1}$, Muhammad, A. ${ }^{1}$, \\ Mohammed K. A. and Umar, $\mathrm{B}^{1}$. \\ ${ }^{I}$ (Department of Human Physiology, Faculty of Medicine, Ahmadu Bello University, Zaria, Kaduna State, \\ Nigeria)
}

\begin{abstract}
The abortifacient role of aqueous extract of Vernoniaamygdalina was investigated by measuring the serum progesterone levels of the experimental animals. 20 female albino rats were grouped into four groups $(n=5)$. Vaginal smear of the rats was taken every morning and viewed under the microscope. Rats in their proestrous cycle were paired with males and their vaginal smear taken the next morning to confirm pregnancy. Group I were treated with normal saline, group II received 200 $\mu \mathrm{g} / \mathrm{ml}$ of standard drug (Misoprostol) and groups III and IV received $250 \mathrm{mg}$ and $500 \mathrm{mg} / \mathrm{ml}$ of aqueous extract of $V$. amygdalina respectively from the $5^{\text {th }}$ $7^{\text {th }}$ days of pregnancy. The rats were observed for a period of 3 weeks. Group I successfully delivered, all group II animals had a complete abortion and groups III and IV had 80\% abortion (one rat delivered in each group while the others had a complete abortion). The serum progesterone levels of the Misoprostol and extract groups showed a significant decrease ( $p>0.05$ ) when compared with group I. But when the serum progesterone levels of extract groups was compared with Misoprostol groups, there was no significant decrease ( $p>0.05)$. This shows that the aqueous extract of Vernoniaamygdalina has an abortifacient effect (80\% effect) which leads to a decrease in the serum progesterone level after abortion (a hormone that is very important for the maintenance of pregnancy).
\end{abstract}

Keywords: Vernoniaamygdalina, rats, pregnancy, progesterone, abortion.

\section{Introduction}

Vernoniaamygdalina is a widely known plant popularly called bitter-leaf, evergreen in nature and flourishes wherever it grows. It is called "ONUGBU" by the Igbos of the eastern part of Nigeria who use it as vegetables, "EWURO" by the Yorubas of the western part of Nigeria who use it for medicine, while the Hausas of northern Nigeria call it "SHIWAKA". The plant is popular for its bitterness, its leaves, stem, roots and bark, therefore the slang name BITTER-LEAF. Dalziel (1937) was about the first to report that the root and twig of the plant are used for the treatment of stomach and gastrointestinal problems by the Hausas of Northern Nigeria, while the decoction from the leaves is used in treating malaria fever in Guinea and Cough in Ghana. In some parts of Nigeria, the stems are used as chew sticks for oral hygiene, and for the management of some dental problems. In Malawi and Uganda, it is used by traditional birth attendants to aid the expulsion of the placenta, after birth, aid post-partum uterine contraction, induce lactation and control post-partum hemorrhage (Bullough and Leary, 1982; Kamatenesi-Mugisha, 2004). Many of these traditional uses of the plant have been scrutinized scientifically. An abortion is the premature termination of pregnancy, either naturally or via medical methods. Further refinements of the term depend on the cause of the abortion (WHO, 1995).

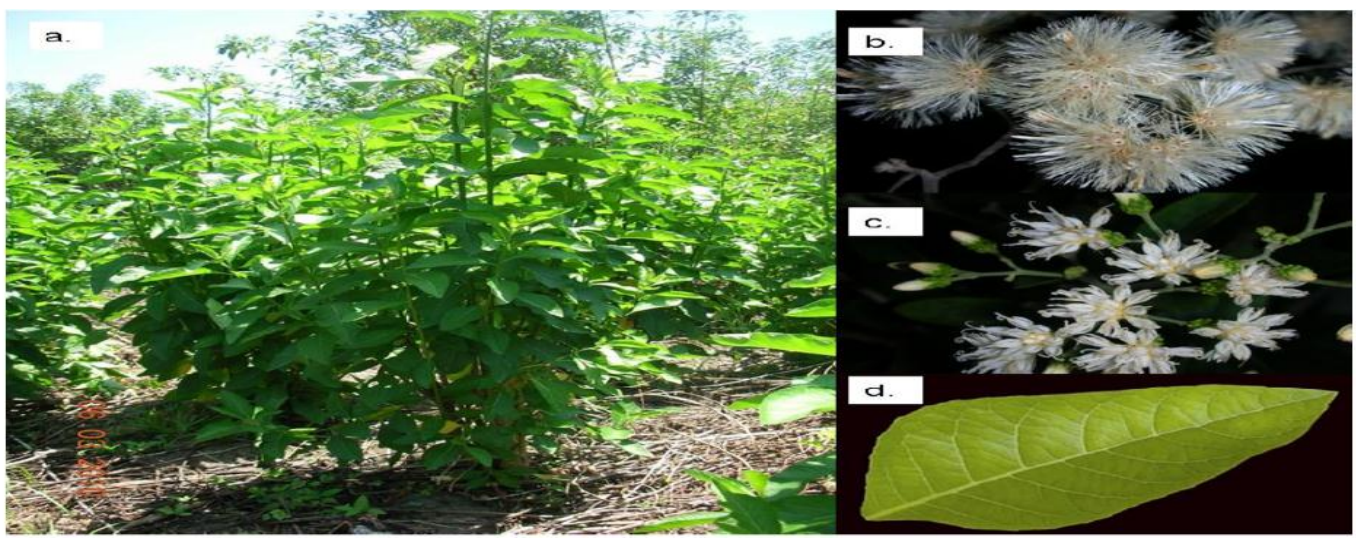

1b.1c. Flower of V. amygdalina 1d. Leaves of V. amygdalina . (Yeap et al., 2010) 


\subsection{Preparation of Plant Material}

\section{Methods}

Vernoniaamygdalina leaves were shade-dried and extracted using distilled water. From $600 \mathrm{~g}$ of fresh leaves, $34.3 \mathrm{~g}$ of extract was obtained after evaporation. The extract was stored in a dessicator until use for the experiment.

\subsection{Phytochemical Screening}

The plant was screened for the presence of various phytochemicals using conventional protocols (Trease and Evans, 1975).

\subsection{Acute Toxicity Study}

$\mathrm{LD}_{50}$ determination was conducted according to the method of Lorke (1983).

\subsection{Animals}

20 female rats and 8 male rats were used for the experiment. The pregnant rats were grouped into four groups, I-IV with 5 rats in each group. The groupings are:
A.Group 1:Control $(1 \mathrm{ml} / \mathrm{kg})$
B. Group 2: Misoprostol $(200 \mu \mathrm{g} / \mathrm{kg})$
C.Group 3: Extract $(250 \mathrm{mg} / \mathrm{kg})$
D.Group 4: Extract $(500 \mathrm{mg} / \mathrm{kg})$

\subsection{Mating Protocol}

Every morning, the vaginal mucus of the female rats was taken using a copper loop. The copper loop was sterilized using distilled water each time it was used for a rat before using it for another rat. The vaginal smear was prepared and viewed under the microscope. Rats in their pro-estrous cycle were paired with males in the ratio of 1:1. After pairing for $24 \mathrm{hrs}$, the vaginal smear was viewed for the presence of spermatozoa which indicates copulation. The day of mating was taken as the first day of pregnancy.

The rats were observed up to the time when the control group delivered (i.e. after a period of about 2025 days of mating). All rats were sacrificed by anesthesia (using chloroform) and blood was taken directly from the left ventricle of the heart. Their uterus was examined for the presence of any implantation. The blood samples were centrifuged in a bench centrifuge at 3000 rev. per min. for 20 minutes. A $2 \mathrm{ml}$ pipette was used to pipette the serum from the cells. The blood plasma was analyzed for the serum progesterone level using progesterone kits in the Department of Chemical Pathology, ABUTH, Shika.

\subsection{Statistical Analysis}

Results were expressed as Mean \pm SEM. Data was analyzed using one way ANOVA. $\mathrm{P}$ value $<0.05$ was considered significant.

\subsection{Phytochemical Screening}

\section{Results}

The preliminary phytochemical analysis of Vernoniaamygdalina leaveextractrevealed the presence of flavonoids, tannins, saponins, resins, alkaloids, reducing sugars and steroid glycosides.

\section{2. $\quad$ Acute Toxicity Study}

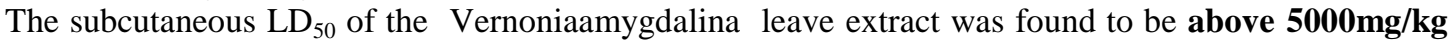
in rats.

\subsection{Pregnancy}

Table :Effects of aqueous extract of vernoniaamygdalina on pregnancy

\begin{tabular}{|c|c|c|c|c|}
\hline \multirow[b]{2}{*}{ Parameter } & \multirow[t]{2}{*}{ Control } & \multicolumn{3}{|c|}{ Continuous administration for 3 days } \\
\hline & & Misoprostol & $\begin{array}{l}250 \mathrm{mg} / \mathrm{ml} \\
\text { Extract }\end{array}$ & $\begin{array}{l}500 \mathrm{mg} / \mathrm{ml} \\
\text { Extract }\end{array}$ \\
\hline Progesterone (ngml ${ }^{-1}$ ) & $20.56 \pm 2.2$ & $5.78 \pm 0.7$ & $10.58 \pm 1.8$ & $12.14 \pm 2.8$ \\
\hline Level of significance & & $\mathrm{S}$ & $\mathrm{S}$ & $\mathrm{S}$ \\
\hline
\end{tabular}




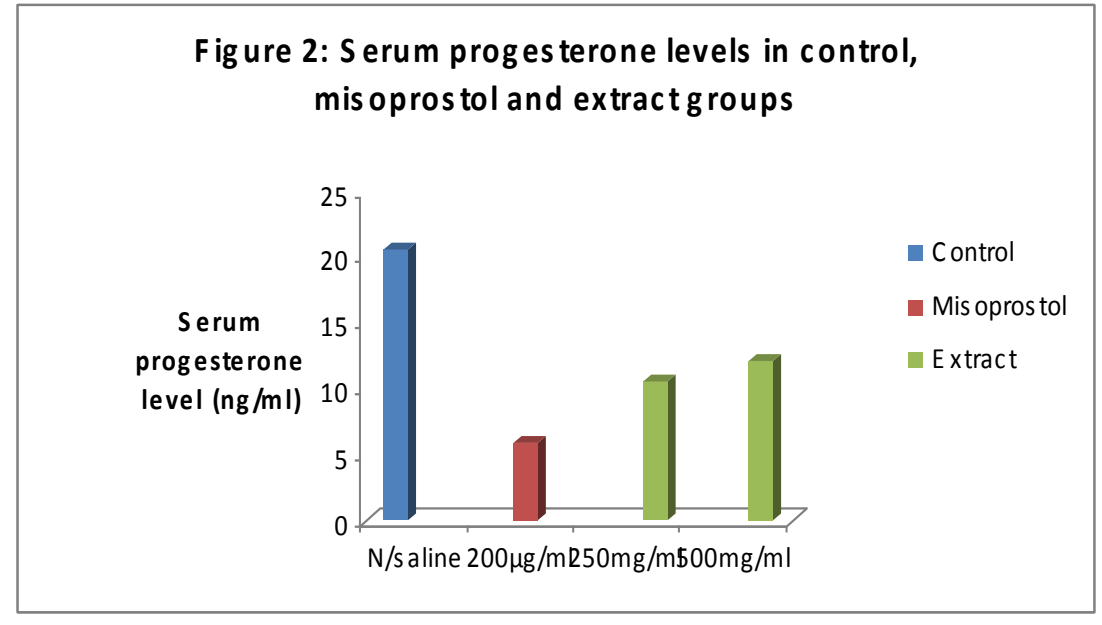

\section{Discussion And Conclusion}

This result is in agreement with previous findings by Chirotaw (2006) who showed that the aqueous extract of V. amygdalinacaused abortion at doses of 2 and $3 \mathrm{~g} / \mathrm{ml}$ and Awe et al. (1999) who showed that the methanol extract of the fresh leaves of V. amygdalina, when admin istered to pregnant mice caused abortion within 24 hours. The mode of action of the plant extract in this research work is not known, but possibly it might be as a result of an increase in uterine contractions in line with previous work by (Kamatenesi-Mugishaet al., 2007) who examined the effects of V. amygdalina and Cleome gynandra on uterine motility. From the $\mathrm{LD}_{50}$ of the plant (up to $5000 \mathrm{mg} / \mathrm{kg}$ ), the plant is safe for human consumption. In the present study, the possible abortifacient effect of aqueous extract of $\mathrm{V}$. amygdalina has shown that the extract has an abortifacient property and decreases the serum progesterone level after abortion. This finding may support the traditional use of the plant as an abortifacient in some parts of Africa.

\section{References}

[1]. Awe, S.O., Makinde, J.M. and Olajide, O.A., (1999). "Cathartic Effect of the Leaf Extract of Vernoniaamygdalina" Fitoterapia 70: $161-165$

[2]. Bullough, C.H.W. and Leary, W. P., (1982). "Herbal Medicines Used by Traditional Birth Attendants in Malawi” Trop. Geograph. Med. 34: 81-85

[3]. Chirotaw, A., (2006). "In Vivo and In Vitro Antifertility Properties of VernoniaAmygdalina" Addis Ababa University School of Graduate Studies, Department of Zoology. P 14

[4]. Dalziel, J.M., (1937). "The Useful Plants of West Tropical Africa" Crown Agents for the Colonies London pp 421-422

[5]. Kamatenesi-Mugisha, M., (2004). "Medicinal Plants used in Reproductive Health Care in Western Uganda: Documentation, Phytochemical and Bioactivity Evaluation" PhD Thesis in Botany, Makerere University, Kampala, Uganda

[6]. WHO (1995). "Complications of Abortion: Technical and Managerial Guidelines for Prevention and Treatment" WHO, Geneva

[7]. Yeap, S.K., Ho, Y.W., Beh, K.B., Liang, S.W., Ky, H., Yousr, N.H.A. and Alitheen, B.N., (2010). "Vernoniaamygdalina, an Ethnoveterinary and Ethnomedical Used Green Vegetable with Multiple Bioactivities" J. of Med. Plants Research 4(25): 2787-2812 